\title{
Effect of pH Value on the Crack Growth Behavior of X70 Pipeline Steel in the Dilute Bicarbonate Solutions
}

\author{
Zhongyu Cui ${ }^{1}$, Zhiyong Liu ${ }^{1, *}$, Liwei Wang ${ }^{2}$, Cuiwei $\mathrm{Du}^{1}$ and Xiaogang $\mathrm{Li}^{1}$ \\ ${ }^{1}$ Corrosion and Protection Center, University of Science and Technology Beijing, Beijing 100083, China \\ ${ }^{2}$ Pipeline Research Institute of China National Petroleum Corporation, Langfang 065000, China
}

\begin{abstract}
In this work, the crack growth behavior of X70 pipeline steel in the near-neutral $\mathrm{pH}$ and acidic solutions was investigated using in-situ crack length measurement, microscopic observation and polarization curves. The results showed that the decrease of the solution $\mathrm{pH}$ promoted the anodic and cathodic reactions simultaneously and accelerate the corrosion rate of X70 steel. This resulted in the blunt crack tip of X70 steel in the acidic environment. The crack growth rate of X70 steel in the acidic solution was lower than that in the near-neutral $\mathrm{pH}$ environment, which was attributed to the higher corrosion rate and the weaker couple effect around the crack tip. [doi:10.2320/matertrans.M2015096]
\end{abstract}

(Received March 6, 2015; Accepted March 30, 2015; Published May 15, 2015)

Keywords: $X 70$ pipeline steel, $p H$, crack growth rate, crack tip

\section{Introduction}

Pipeline stress corrosion cracking (SCC) has been one of the vital threats to safety of pipeline operation. The pipelines have generally experienced two main forms of SCC, i.e. high $\mathrm{pH}$ and near-neutral $\mathrm{pH}$ SCC. ${ }^{1-5)}$ To date, there have been extensive researches performed to investigate the crack growth behavior of pipeline steels in theses two environments. ${ }^{6-10)}$ In the high $\mathrm{pH}$ environment, the crack growth rate can be simply calculated by the anodic dissolution rate using Faraday law. ${ }^{10}$ ) In the near-neutral $\mathrm{pH}$ solution, however, the crack growth rate is difficult to simulate because of the significant effect of the absorbed $\mathrm{H}$ atoms. ${ }^{11)}$ The crack growth rate of pipeline steels in the near-neutral $\mathrm{pH}$ environment has been investigated using the direct reading method, ${ }^{7)}$ the direct/alternating current potential drop method, ${ }^{6)}$ or the in-situ observation method. ${ }^{12)}$ Chen $^{6)}$ reported that crack growth of pipeline steels in near-neutral $\mathrm{pH}$ environments was consistent with that of true corrosion fatigue, and the crack growth rate $\mathrm{d} a / \mathrm{d} N$ can be correlated with $K_{\max } \Delta K f^{-0.1}$. Lu ${ }^{11)}$ also proposed a predictive model on the basis of the assumption that the cracking was dominated by corrosion fatigue mechanism enhanced by hydrogen embrittlement. In the actual field environments, the pipelines are also subjected to the acidic soils with a low $\mathrm{pH}^{.2-14)}$ Wang $^{12)}$ investigated the crack growth behavior of X80 steel in the acidic solution and reported that crack growth rate was accelerated with the decreasing solution $\mathrm{pH}$. However, the reasons for these effects have not been established unambiguously.

The background electrolyte and mechanical stress values are highly important when studying of the effects of solution $\mathrm{pH}$ on the SCC process in pipeline steel. NS4 solution, ${ }^{15}$ ) after being purged with an inert gas containing $5 \% \mathrm{CO}_{2}$, is frequently used as the working electrolyte while studying the near-neutral $\mathrm{pH}$ SCC of pipeline steel. In this work, the acetic acid solution ( 5 mass \%) was introduced to adjust the $\mathrm{pH}$ value of the NS4 solution to 4.0. The effect of the solution $\mathrm{pH}$ on the crack growth behavior of X70 steel was investigated

*Corresponding author, E-mail: liuzhiyong7804@126.com using the in-situ crack propagation test, microscopic observation and polarization curves.

\section{Experimental}

\subsection{Material and solution}

The X70 pipeline steel was used in this study, the chemical composition (mass\%) of which was as follows: $0.065 \mathrm{C}, 1.57$ $\mathrm{Mn}, 0.23 \mathrm{Si}, 0.2 \mathrm{Ni}, 0.18 \mathrm{Cr}, 0.22 \mathrm{Cu}, 0.056 \mathrm{Nb}, 0.002 \mathrm{~S}$ and $0.0019 \mathrm{P}$. The yield strength of the material was $490 \mathrm{MPa}$, and its ultimate tensile strength was $610 \mathrm{MPa}$. The solution used in this work was a near-neutral pH solution (NS4), which was typically used to simulate the electrolyte trapped under a disbonded coating. The chemical composition of the solution was: $\mathrm{CaCl}_{2} \cdot 2 \mathrm{H}_{2} \mathrm{O} 0.181 \mathrm{~g} / \mathrm{L}, \mathrm{KCl} 0.122 \mathrm{~g} / \mathrm{L}$, $\mathrm{MgSO}_{4} \cdot 7 \mathrm{H}_{2} \mathrm{O} 0.131 \mathrm{~g} / \mathrm{L}$ and $\mathrm{NaHCO}_{3} 0.483 \mathrm{~g} / \mathrm{L}$. To investigate the influence of $\mathrm{pH}$ on the crack growth behavior of X70 steel, the acetic acid solution ( 5 mass $\%$ ) was introduced to adjust the $\mathrm{pH}$ value of the NS4 solution to 4.0. Prior to test, all the solutions were purged with $5 \% \mathrm{CO}_{2}+95 \% \mathrm{~N}_{2}$ for $4 \mathrm{~h}$ and the gas purging was maintained throughout the test.

\subsection{Crack growth test}

Compact tension specimens (CT) were used for the crack growth test of X70 pipeline steel. The specimens were made in accordance with ASTM E647, ${ }^{16)}$ with the machined notch perpendicular to the rolling direction of the steel. The detailed sizes are shown in Fig. 1. The machined CT specimen was pre-cracked by fatigue in air for the initiation of a sharp crack tip from the machined notch. The crack length on both sides was controlled at $2.5 \mathrm{~mm}$ long, and the total crack length from the loading line (including the notch) was typically $30.5 \mathrm{~mm}$ at the surface in this case. After pre-cracking, the specimen was cyclically loaded in the near-neutral $\mathrm{pH}$ solution. A triangle waveform was used with a loading frequency of $0.002 \mathrm{~Hz}$ and a stress ratio of 0.625 . The maximum stress was controlled to achieve a maximum stress intensity factor $\left(K_{\max }\right)$ of $72.87 \mathrm{MPa} \cdot \mathrm{m}^{0.5}$ and the stress intensity factor range $(\Delta K)$ was $27.3 \mathrm{MPa} \cdot \mathrm{m}^{0.5}$. These values were calculated according to the following equation in ASTM E647: ${ }^{16)}$ 

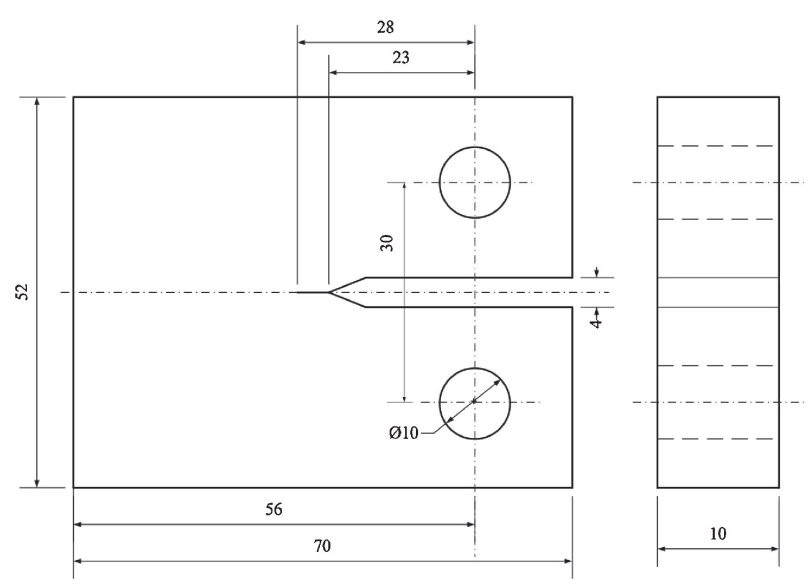

Fig. 1 Geometry of the compact specimen used in this work.

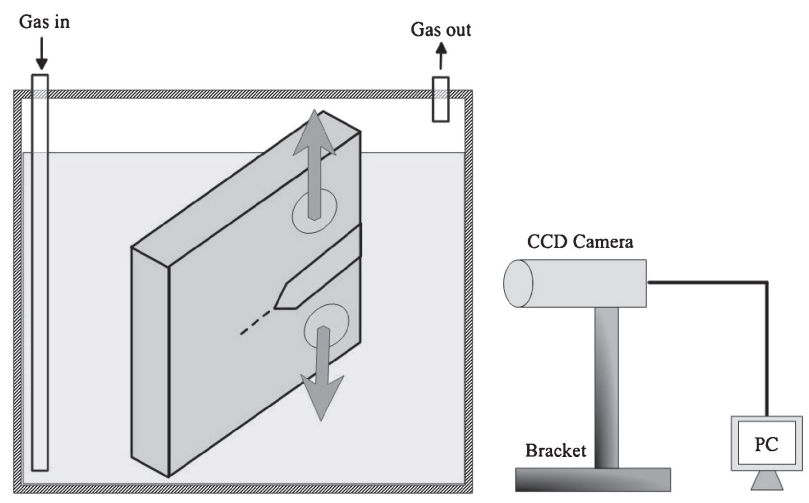

Fig. 2 Schematic diagram of crack length measurement systems.

$$
\begin{aligned}
K= & \frac{P}{B W^{1 / 2}} \cdot \frac{(2+\alpha) \alpha^{1 / 2}}{(1-\alpha)^{3 / 2}} \\
& \cdot\left[0.886+4.64 \alpha-13.32 \alpha^{2}+14.72 \alpha^{3}-5.6 \alpha^{4}\right]
\end{aligned}
$$

where $K$ is the stress intensity factor, $P$ is the applied load, $B$ is the thickness of the specimen, $W$ is the width of the specimen and the coefficient $\alpha=a / W$ ( $a$ is the crack length).

The crack growth of the X70 pipeline steel was monitored through an in-situ observation system (Fig. 2), which has been used in investigating the crack growth behavior in the literatures. ${ }^{17)}$ The surface of the CT specimen during the crack growth test could be observed by using a highperformance charge-coupled device (CCD) camera system. In order to track the tip of the crack, the head part of the CCD camera was mounted on an X-Z stage. The system was operated using a computer and it was confirmed that reasonably clear images of the crack growth behavior could be obtained in the test.

\subsection{Microscopic observation}

For one of the parallel tests, the CT specimen was taken off before the unstable fracture. Then, the growth paths of the $\mathrm{X} 70$ steel in the two solutions were observed using a stereology microscope (KEYENCE VHX2000). After that, the crack tip region was cut off and ground through successive grades of silicon carbide abrasive papers from P120 to P2000 followed by diamond finishing to $0.1 \mathrm{~mm}$. Then the specimen was etched in $5 \% \mathrm{HNO}_{3}+95 \% \mathrm{C}_{2} \mathrm{H}_{5} \mathrm{OH}$

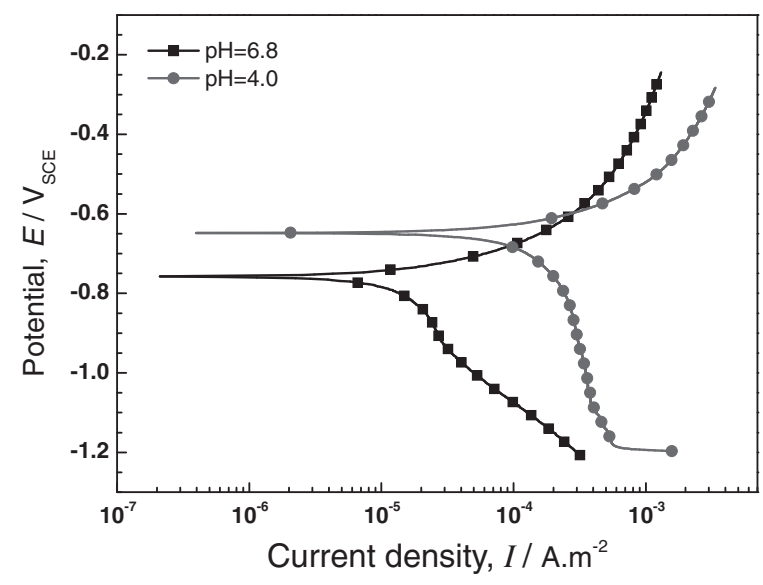

Fig. 3 Potentiodynamic polarization curves of X70 steel in near-neutral pH and acidic solutions.

to observe the morphology of the crack tip area clearly on the scanning electron microscopy (SEM, Quanta 250).

\subsection{Electrochemical measurements}

The work electrodes for electrochemical tests were embedded in epoxy resin leaving a working area of $1.0 \mathrm{~cm}^{2}$. The working surface was ground down to 1500 grit and then degreased by acetone followed by cleaning in ethanol. Electrochemical measurements were performed with a PARSTAT 2273 electrochemical workstation in a conventional three-electrode cell, using a platinum sheet as a counter electrode and a saturated calomel electrode as reference electrode. Potentiodynamic polarization curves were measured in the two solutions with the scan rate $0.333 \mathrm{mV} / \mathrm{s}$. It was repeated at least three times to maintain the reproducibility.

\section{Results}

\subsection{Polarization curves}

Figure 3 shows the potentiodynamic polarization curves of X70 steel in near-neutral $\mathrm{pH}$ and acidic solutions. Both the anodic and cathodic reactions, especially the latter, are accelerated as the solution $\mathrm{pH}$ decreases. This results in the positive shift of the corrosion potential from $-0.75 \mathrm{~V}$ to $-0.65 \mathrm{~V}$ and the increase of the corrosion rate from $2.46 \times$ $10^{-5} \mathrm{~A} / \mathrm{cm}^{2}$ to $1.89 \times 10^{-4} \mathrm{~A} / \mathrm{cm}^{2}$.

\subsection{Crack length and crack growth rate}

Figure 4 shows the increase of the crack length during the crack propagation tests in near-neutral $\mathrm{pH}$ and acidic solution environments. The crack length increases gradually with increasing of the test time, with a quick increase in the later stages of the cyclic load tests. The facture time and the mean crack growth rate (CGR) are calculated and shown in Fig. 5. The results indicate that the crack growth rate in the solution with a $\mathrm{pH}$ of 4.0 is much lower than that in the near-neutral $\mathrm{pH}$ environment.

Figure 6 shows the CGR in terms of $\mathrm{d} a / \mathrm{d} t$ (a) and $\mathrm{d} a / \mathrm{d} N$ (b) as a function of $\Delta K$ in the two solution environments, in which the black and red lines illustrate the variation tendency of this parameter during the test. The $\mathrm{d} a / \mathrm{d} t$ and $\mathrm{d} a / \mathrm{d} N$ 


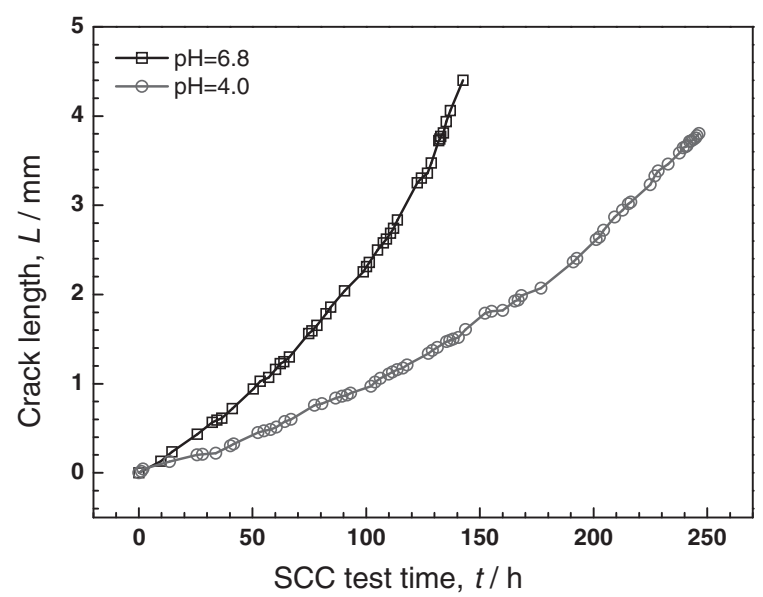

Fig. 4 Crack length of the X70 steel during the crack growth tests in nearneutral $\mathrm{pH}$ and acidic solutions.

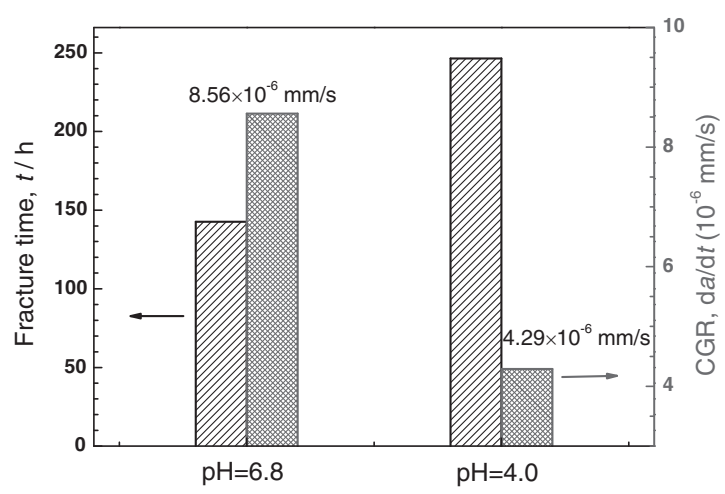

Fig. 5 The facture time (left column) and the mean crack growth rate (right column) of X70 steel in the near-neutral $\mathrm{pH}$ and acidic solutions.

increase abruptly in the lower $\Delta K$ and then increases linearly as the $\Delta K$ augments. As illustrated in our previous work, ${ }^{18)}$ this phenomenon could be considered as the intermediate behavior between corrosion fatigue that followed a Paris law behavior and $\mathrm{SCC},{ }^{3)}$ where the crack growth rate was independent of $\Delta K$. In addition, the CGR in the near-neutral $\mathrm{pH}$ environment is significantly higher than that in the acidic solution

\subsection{Crack paths and crack tips observation}

Figure 7 shows the crack paths of the CT specimens in near-neutral $\mathrm{pH}$ and acidic solutions. It is seen that the crack of the sample in the acidic solution is wider than that in the near-neutral $\mathrm{pH}$ environment, attributing to the pronounced anodic dissolution of the crack walls. The crack tip areas of the two specimens are carefully observed and the results are shown in Fig. 8. A circular crack tip with a radius of a few micrometers is detected for the specimen exposed to the acidic solution (Fig. 8(b)). In contrast, the crack tip remains sharp after testing in near-neutral $\mathrm{pH}$ environment, indicating a relatively lower resistance to the crack propagation.

\section{Discussion}

It has been acknowledged that the anodic dissolution and hydrogen ingress into the steel are involved in the crack
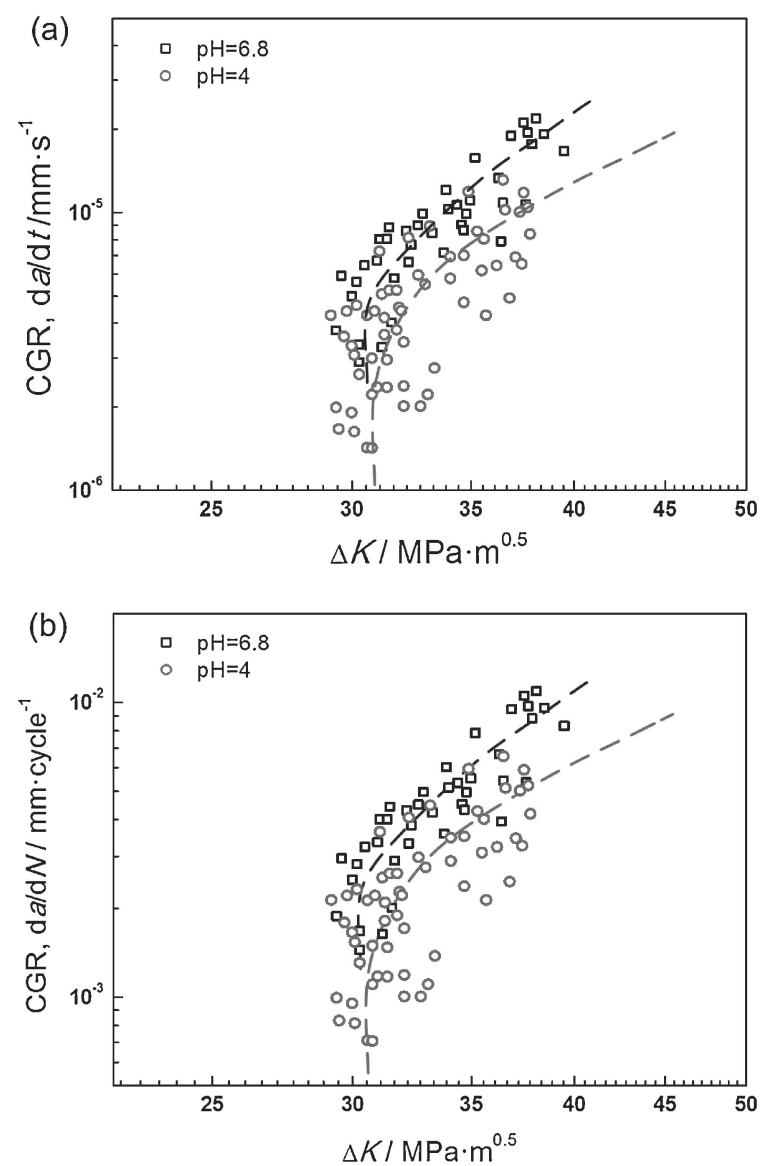

Fig. 6 Crack growth rate of X70 steel in terms of $\mathrm{d} a / \mathrm{d} t$ (a) and $\mathrm{d} a / \mathrm{d} N(\mathrm{~b})$ as a function of $\Delta K$.

growth mechanism of pipeline steel in near-neutral $\mathrm{pH}$ environment. ${ }^{4,15,19)}$ Both of them contribute to the crack growth during the cyclic load. ${ }^{20}$ In this work, the crack growth rate of X70 steel in the acidic solution is much lower than that in the near-neutral $\mathrm{pH}$ environment. It can be explained by the following reasons. Firstly, the corrosion rate is intimately linked with the crack growth rate. Beavers ${ }^{5)}$ found a general trend of increasing crack velocity with decreasing corrosion rate in the soil/electrolyte environments. In the acidic solution, the corrosion rate is significantly enhanced (Fig. 3), resulting in a blunt crack tip. This can be observed in Fig. 8(b), which is a physical indication of crack dormancy. In this case, the crack propagation is inhibited. Secondly, it has been reported that the galvanic effect between the crack tip and crack wall is important in promoting the crack growth. ${ }^{20)}$ In the nearneutral $\mathrm{pH}$ environment, as confirmed in our previous work, the $\mathrm{pH}$ of the solution in the crack tip region is about 4.0. ${ }^{18)}$ This creates a pronounced couple effect between the crack tip and crack wall due to the difference of the solution $\mathrm{pH}$. In this case, the fresh metal surface in the crack tip corrodes severely, which results in the corrosion-facilitated plasticity and thus enhances the crack propagation. As for the situation in the acidic solution with a $\mathrm{pH}$ of 4.0 , the $\mathrm{pH}$ of the solution around the crack tip is also about 4.0 , which is similar with the bulk solution. Therefore, no obvious galvanic effect is expected and the crack growth is not promoted. 

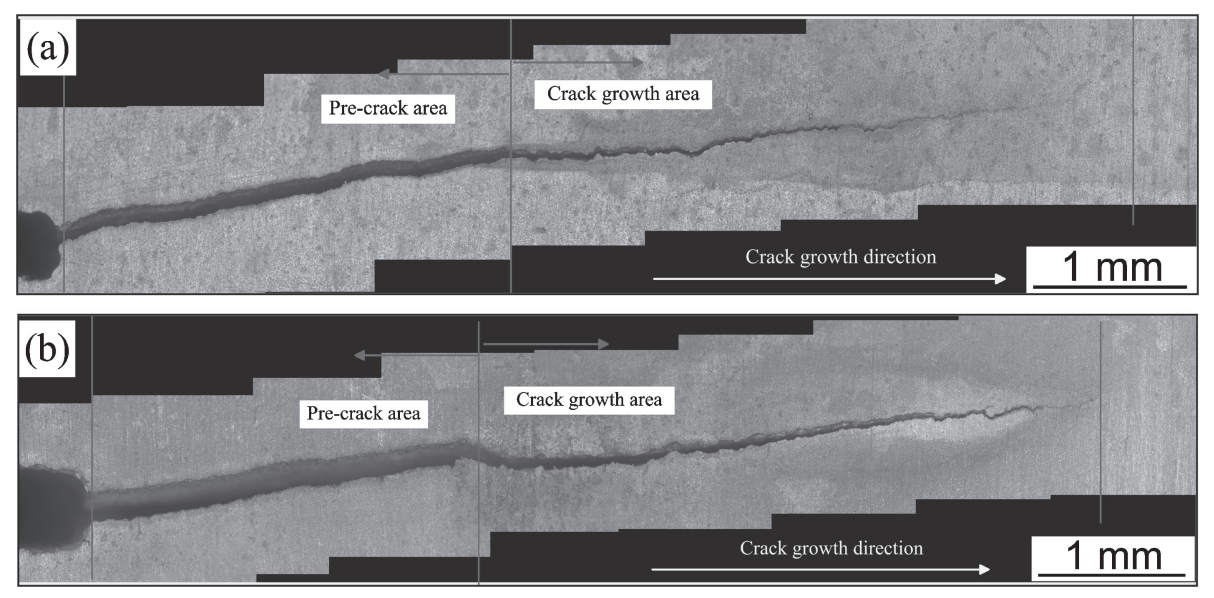

Fig. 7 Crack paths of the CT specimens in near-neutral $\mathrm{pH}$ (a) and acidic solution environments (b).
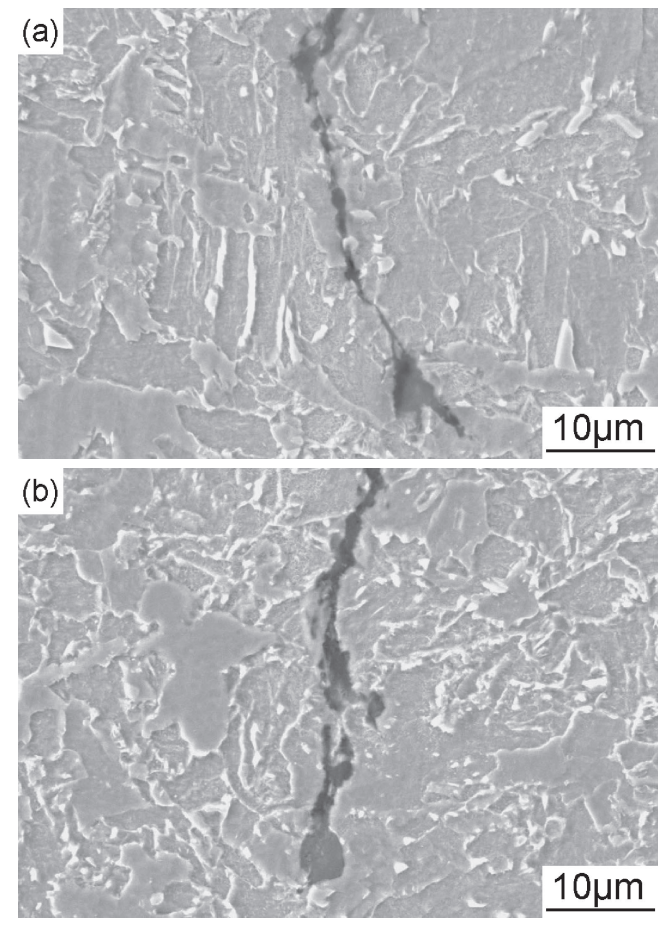

Fig. 8 Comparison of crack tip morphology for two tests conducted in the near-neutral $\mathrm{pH}$ solution (a) and acidic solution (b).

\section{Conclusion}

(1) Decrease of the solution $\mathrm{pH}$ promotes the anodic and cathodic reactions simultaneously and accelerates the corrosion rate of X70 steel.

(2) Crack growth rate of the $X 70$ steel in the acidic solution is much lower than that in the near-neutral $\mathrm{pH}$ environment, which is attributed to the higher corrosion rate and the weaker couple effect around the crack tip.

(3) Crack tip of the X70 steel in the near-neutral pH environment is sharp during the crack propagation, while that in the acidic solution tends to be blunt.

\section{Acknowledgement}

The authors wish to acknowledgement the financial support of National Natural Science Foundation of China (No. 51471034 and No. 51131001), National Basic Research Program of China (973 Program project, No. 2014CB643300) and National Environmental Corrosion Platform (NECP).

\section{REFERENCES}

1) R. N. Parkins: CORROSION, (NACE, 2000) Paper no. 00363.

2) J. A. Beavers and B. A. Harle: J. Offshore Mech. Arct. Eng. 123 (2001) $147-151$.

3) J. A. Beavers: Corrosion 70 (2013) 3-18.

4) Z. Y. Liu, X. G. Li and Y. F. Cheng: Corros. Sci. 55 (2012) 54-60.

5) J. A. Beavers, D. M. Owen, C. L. Durr, B. Delanty and R. Sutherby: CORROSION, (NACE, 2001) Paper no. 01217.

6) W. Chen and R. L. Sutherby: Metall. Mater. Trans. A 38 (2007) 12601268.

7) R. Eadie, K. Szklarz and R. Sutherby: Corrosion 61 (2005) 167-173.

8) A. Marshakov, V. Ignatenko, R. Bogdanov and A. Arabey: Corros. Sci. 83 (2014) 209-216.

9) F. King, T. R. Jack, W. Chen, M. J. Wilmott, R. R. Fessler and K. Krist: CORROSION, (NACE, 2000) Paper no. 00361.

10) B. Lu, F. Song, M. Gao and M. Elboujdaini: Corros. Sci. 52 (2010) 4064-4072.

11) B. Lu: Fatigue Fract. Eng. Mater. Struct. 36 (2013) 660-669.

12) X. Z. Wang, Z. Y. Liu, X. Ge, X. L. Zhan, C. W. Du and X. G. Li: Corrosion 70 (2014) 872-879.

13) Z. Y. Liu, X. G. Li, C. W. Du, G. L. Zhai and Y. F. Cheng: Corros. Sci. 50 (2008) 2251-2257.

14) L. W. Wang, X. G. Li, C. W. Du, P. Zhang and Y. Z. Huang: J. Iron Steel Res. Int. 22 (2015) 135-144.

15) R. N. Parkins, W. Blanchard, Jr. and B. Delanty: Corrosion 50 (1994) 394-408.

16) ASTM E647: The American Society for Testing of Materials (2005).

17) K. R. Cooper and R. Kelly: Corros. Sci. 49 (2007) 2636-2662.

18) Z. Y. Cui, Z. Y. Liu, Q. Li, L. W. Wang, X. Z. Wang, C. W. Du and X. G. Li: Corrosion Science, (2015) submitted.

19) B. Gu, J. Luo and X. Mao: Corrosion 55 (1999) 96-106.

20) W. Zhao, R. Xin, Z. He and Y. Wang: Corros. Sci. 63 (2012) 387-392. 